\title{
Growing a photonics program in good times and bad
}

\section{Judith Donnelly, Randall Seebeck}

Judith Donnelly, Randall Seebeck, "Growing a photonics program in good times and bad," Proc. SPIE 9663, Eighth International Topical Meeting on Education and Training in Optics and Photonics, 96630C (6 October 2003); doi: $10.1117 / 12.2207338$

SPIE Event: Eighth International Topical Meeting on Education and Training in Optics and Photonics, 2003, Tucson, Arizona, United States 


\title{
Growing a photonics program in good times and bad
}

\author{
Judith Donnelly and Randall Seebeck \\ Three Rivers Community College 574 New London Turnpike, Norwich, CT 06030 \\ jdonnelly@trcc.ccommnet.edu
}

\begin{abstract}
Three Rivers Community College began an associate degree program in Photonics Engineering Technology in 1998 when telecommunications was booming. Five years later the program continues to grow. Support from industry and from the National Science Foundation have been key to keeping the program moving forward. Creating a pipeline of entering students remains a challenge.

(C) 2003 Optical Society of America

OCIS codes: $(000.0000)$ General
\end{abstract}

\section{Introduction}

Three Rivers Community College (TRCC) is a public, associate degree-granting college located in southeastern Connecticut.. Formed in 1992 by the merger of Thames Valley State Technical College and Mohegan Community College, TRCC is a comprehensive multi-campus college with a full range of programs in technology and engineering technology. Although Connecticut is located in what has been called "Photonics Valley", stretching from Virginia to Massachusetts, eastern Connecticut has few optics related companies and is mainly known for two large Indian gaming casinos and the submarines built at General Dynamics Electric Boat Division in Groton. Yet TRCC has created a two-year associate degree program in Photonics Engineering Technology which continues to grow. This paper describes the development of a photonics technician program at a distance (in Connecticut terms) from supporting industries and explains strategies used to keep the program current with industry and student expectations.

\section{The first few years}

\subsection{Initial program development and approval}

The Three Rivers' Photonics Engineering Technology (PET) program resulted from one of the authors (JD) growing restlessness after many years of teaching mainly Newtonian physics to technology students. A course in optics and modern physics had been discontinued in the late 1980s and, around the same time, a conversion from a quarter to a semester calendar reduced the number of students taking second semester physics, which included waves, sound and light. An offer to participate in a National Science Foundation Advanced Technology Education (NSF-ATE) supported professional development project in fiber optics technology was thus greeted with enthusiasm.

The Fiber Optics Technology Education Project (FOTEP) was administered by the New England Board of Higher Education (NEBHE), and the Fall 1995 FOTEP workshop was the beginning of a long and fruitful relationship between TRCC and NEBHE. Held at Springfield (MA) Technical Community College, the workshop introduced participants to fiber optics technology and its seemingly boundless career opportunities. Each participating school was given a set of tools and a test set for fiber connectorization (half paid for by the grant and half by the participating institution) and each participating teacher practiced using the equipment to terminate multimode cables with ST connectors. The participants were then instructed to incorporate the new knowledge into their own courses. Additional workshops held in the summers of 1996 and 1997 provided participants with more detailed information on fiber optic communications systems and gave them the opportunity to network with each other and with FOTEP's industry advisors.

At TRCC, the FOTEP workshop led initially to the creation of a four credit laboratory course, Introduction to Photonics, which was offered as a technical elective course to interested students. The publication of the first National Photonics Skills Standards [1], and the prediction that the number of photonics technician jobs would double in the coming few year prompted TRCC Dean of Technical Education Thomas Kidd to convene a Photonics Steering Committee in March 1996. The five companies represented at the initial meeting were engaged in the design, manufacture, or installation of fiber optic systems and components, and each enthusiastically endorsed the idea of a two year degree to train photonics technicians. Notes from the first steering committee meeting indicate that industry representatives declined to review the detailed skills standards, but preferred to create a short list of characteristics desired in a new employee. Committee members were anxious that students be proficient in geometry 
and trigonometry, have well developed English communications skills, be good "team players", and have positive "work ethics" training. Basic optics and electronics lab skills were desirable, but each company suggested that they would prefer to train employees on their own systems and to their own standards.

The actual curriculum development proceeded along practical lines: the program was to cost as little as possible to develop and administer, while meeting the guidelines of both the Community Technical Colleges and the Department of Higher Education. The former had a strict 68 credit limit for associate degree programs, and the latter an interest in balanced programs with a large percentage of general education credits. The PET program was created through compromise; existing courses from Electrical Engineering Technology were supplemented by courses in laser safety, optics, lasers and fiber optics. The optics/photonics courses, each of which has a laboratory component, were designed with assistance from the Laser Electro Optics Technology program at Springfield Technical Community College. Following the requirements of the Electrical Engineering Technology program, the math sequence proceeded from PreCalculus through Calculus II, and the program included seven electrical/electronics courses. Initially, little was done to integrate the existing electronics courses with the new photonics courses.

The program was enthusiastically approved by the Community College Board of Trustees in December, 1996. The approval of the Department of Higher Education followed six months later. The June approval precluded recruiting a class for Fall 1997, nonetheless, the first optics course was offered in September 1997 to approximately 10 students, four of them declared PET majors or Electrical Engineering Technology double majors.

\subsection{The first laboratory}

For the first two years, laboratory experiments were performed in a variety of locations, including the physics and electricity/electronics labs. FOTEP had provided hand tools and an LED test source and meter for applying connectors to fiber optic cable, and the physics lab had a variety of light sources, including HeNe lasers and inexpensive optical components and mounts. The first priority was to obtain basic equipment for optics and fiber optics.

In 1997, Three Rivers became a partner in the newly created Northeast Center for Telecommunications Technologies (NCTT, now the National Center for Telecommunications Technologies), an NSF-ATE Center located at Springfield Technical Community College and created in partnership with NEBHE. NCTT provided professional development workshops, as well as funding for partner schools to assist in starting new courses and programs. At Three Rivers, NCTT grant funds were used to purchase additional tools and test equipment for fiber optics as well as a small optical breadboard, components and hardware. Funding was also used to create marketing brochures and to hire student technicians to assist with setting up and testing newly developed laboratory experiments.

By the fall of 1998, it was evident that more appropriate space was needed. Room darkening shades had been added to the physics laboratory, but if was impossible to completely block sunlight from entering the large south facing windows. A small darkroom, once the technical college's yearbook photography lab, became the first dedicated optics lab. After extensive cleaning, the walls were painted flat black and a green safelight was installed for use with red sensitive holography film.

\section{Growing in industry boom times}

\subsection{Marketing}

The years from 1998 to 2001 saw rapid growth in the program as measured by enrollment and acquisition of laboratory equipment. Enrollment surged from 4 students in the spring of 1998 to 35 in the fall of 2001. Several marketing initiatives contributed to this growth.

- High school mailings: Since photonics was a new and unknown word, marketing materials were developed, including a poster and brochure. These were distributed to teachers and guidance/career counselors at the 20 high schools in the college's Tech Prep consortium. Teachers were invited to bring students to visit the College for demonstrations and lab tours.

- Appeal to graduates: A list of recent graduates in the Electrical Engineering Technology program was obtained, and a special informational mailing invited graduates to earn a second degree with "only four more courses". Similar information was made available at the U.S. Naval Submarine Base, also located in southeastern Connecticut.

- Industry awareness: Using various resources including the Internet and telephone and industry directories, a mailing list of Connecticut photonics related industries was created. A newsletter was produced to bring 
awareness of the new degree program to companies that might provide support through donations of materials or hiring program graduates. A newsletter is still sent out to the industry mailing list and to high schools in eastern Connecticut approximately twice a year. The newsletter includes information about program activities, curriculum changes, and student awards and achievement, and it publicly acknowledges companies that have provided assistance such as hosting tours or making donations.

- JDS Uniphase Scholarship: From 1999- 2001, JDS Uniphase/Electro Optics Products Group (Bloomfield, CT) offered one new scholarship each semester to a Photonics Engineering Technology student. The award covered all costs of the degree, including tuition, fees, books and required supplies, a total of approximately $\$ 3500$ per year per student. Not only did the scholarship bring excellent new students to the program, it also created a superb marketing opportunity, since newspapers and high school guidance offices actively promote scholarship opportunities.

The program continued to expand in other ways. In response to an invitation received by mail in Fall 1998, PET students requested permission to form a chapter of SPIE, the International Optical Engineering Society. By Spring 1999 a constitution and bylaws had been written and the group sought and received operational funds from the college's Student Government. This funding supported field trips to companies throughout Connecticut and Massachusetts and provided gifts for industry speakers who addressed the group on campus.

The SPIE student chapter rapidly became the outreach arm of the program. Not only does it continue to fund yearly trips to industry and trade shows such as Photonics East and the New England Fiber Optics Council's Fiberfest, but it is also a visible group on campus, raising awareness of the program and photonics technology. In 2001, the chapter received a grant from SPIE which was used to create an "educational light show" with a script describing optics technology and careers and special effects and music to appeal to a high school audience. The show is a regular stop for visiting high school groups, and students have taken it to other venues as well, including two appearances at a regional conference of the Technology Student Association. The chapter has also conducted fundraisers for a chapter volunteer excellence award, and in 2003, they invited the college community to join them in an event to celebrate Worldwide Pinhole Camera day. Each event provides the opportunity to leaflet both campuses with signs bringing attention to both the SPIE student chapter and the PET program.

In addition to day and evening credit courses, non-credit hands-on fiber optics workshops were developed through the college's Continuing Education department. Introductory and Advanced workshops continue to be taught yearly, attracting students from business, industry and the military. Teachers in area high schools have also been invited to attend at no cost, with expenses paid by the college's Tech Prep program.

\subsection{Laboratory improvement}

In 1998 the program received a $\$ 51,000$ grant from the National Science Foundation Instrumentation and Laboratory Improvement program (NSF-ILI) for the development of a laboratory for lightwave communications. The grant allowed the creation of three lab stations: two stations for fiber splicing and test and a station for demonstrating wavelength division multiplexing at $1310 \mathrm{~nm}$ and $1550 \mathrm{~nm}$. Along with the fiber termination equipment previously obtained from the FOTEP project and NCTT, two fusion splicers and two optical time domain reflectometers (OTDRs) were purchased to allow students to create and test long fiber links. Two fiber coupled lasers and WDM couplers were purchased, and JDS Uniphase donated lithium niobate modulators. Table 1 lists the equipment specified for the Lightwave Communication Laboratory. Note that the cables were donated by NCTT and Chromatic Technologies, allowing additional equipment to be purchased with grant funds. Chromatic Technologies also donated two additional older model OTDRs. Older models of equipment are usually of a simpler design and allow a more straightforward introduction to an instrument before the more complex menu driven instrument is used.

Although the college was obliged to match only the dollar amount of the equipment grant, a large college overmatch plus a round of industry donations brought an assortment of lasers, components, mounts, optical rails, and breadboards to the program. A $5^{\prime} \times 8^{\prime}$ optical table was purchased for the small darkroom (now known as the Holography/Interferometry Lab). While most donations were accepted enthusiastically, one particularly large "gift" emphasized the need for caution when accepting industry donations. The college had been informed of a large quantity of fiber and "associated components" being surplussed by a large company. The fiber optics course and the Continuing Education fiber optics workshops have a constant need for optical fiber, since students consume fiber and cables while practicing splicing and connector application. After examining the list of available items, the college expressed a desire to accept the some of optical fiber. The actual donation consisted of several dozen large, sealed boxes, some containing hundreds ferules and obsolete fiber connectors, hundreds of specialty electronic 
connectors, boxes of colored coating pellets and bags of unidentifiable parts. There were indeed several hundred spools of fiber included, but since all identifying marks had been removed they were of value only for an exercise in identification of unknown fiber. As a result of this experience, donations, while still gratefully received, are thoroughly investigated before acceptance.

Table 1 Lightwave Communication Laboratory

\begin{tabular}{|l|l|}
\hline \multicolumn{2}{|l|}{ Station 1 and 2: Fiber splicing and test } \\
\hline 2 & Siecor compact fusion splicer kit \\
\hline 2 & $850,1310,1550 \mathrm{~nm}$ laser source \\
\hline 2 & Fiber optic power meter (multi wavelength) \\
\hline 2 & Visible fault locator \\
\hline 2 & HP Mini OTDR mainframe with floppy drive \\
\hline 4 & cable: $2.2 \mathrm{~km}$ singlmode fiber reel connectorized at one end \\
\hline 1 & cable: $300 \mathrm{~m}$ multimode cable \\
\hline 1 & cable: 300 singlemode cable \\
\hline 2 & $3 \mathrm{M}$ mechanical splice tool \\
\hline Station $3:$ & WDM \\
\hline 1 each & LiNiO2 Integrated Optical Modulators $1550 \mathrm{~nm}$ and $1310 \mathrm{~nm}$ \\
\hline 1 each & Fiber coupled diode lasers, $1550 \mathrm{~nm}$ and $1310 \mathrm{~nm}$ \\
\hline 2 & Fiber coupled high speed detectors with BNC adapter \\
\hline 2 & HP arbitrary waveform generator \\
\hline 2 & HP High speed digital storage oscilloscope \\
\hline 1 & HP RF Spectrum Analyzer \\
\hline
\end{tabular}

The shared physics and electronics laboratories were clearly inadequate to house all the new equipment. An under utilized electronics laboratory was remodeled into classroom/laboratory space to house the program laboratories. Walls were painted dark charcoal gray and room darkening shades were purchased for the large windows. Movable wooden screens were built to serve as laser beam blocks. The adjoining faculty office allowed the classroom to be used between classes by students, who were encouraged to use the space to study, for internet access or to work on projects. Allowing students to use the classroom space to work together during their free time fosters a feeling of belonging. As one student stated, "We're the only program that has its own 'club house'." Nearby instructors are able to provide assistance when needed and ensure that rules are obeyed.

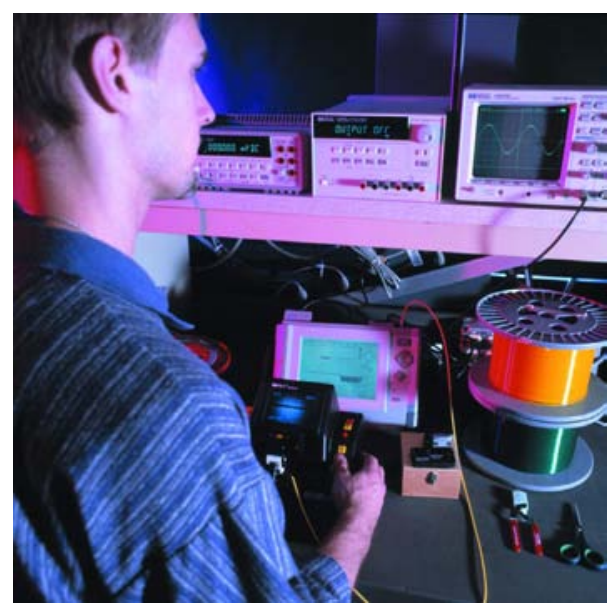

Fig..1 Students practice fiber splicing and use of the OTDR in the Lightwave Communications Lab (1999) 


\subsection{Curriculum revisions}

The original Photonics Steering Committee was reconstituted as the Photonics Engineering Technology Industry Advisory Committee. Meeting once a year, the committee members make suggestions to keep the curriculum relevant to current industry trends. Members also assist throughout the year by responding to requests for information used for accreditation reports and evaluations by the college. The committee has been an invaluable resource for school-to-career opportunities such as tours, speakers and internships, and its members have provided technical advice and assistance securing donations and other forms of support. At the October 1999 meeting, the Industry Advisory Committee endorsed the creation of an Advanced Laser Topics course to be taken by students during the last semester of the program. The course is used to explore topics of current interest and to give students the opportunity to work individually on projects such as building a $\mathrm{CO}_{2}$ laser or assembling a fiber optic WDM system. An advanced course from the Electrical Engineering Technology was eliminated to add the course without increasing the number of credits.

Even before the telecommunications downturn, it was apparent that some students were excited by optics but not interested in the depth of electrical/electronics courses of the PET curriculum. The associate in applied science (AAS) in General Engineering Technology (GET) provided a suitable pathway for such students. The GET program consists of a core of math, science, technology and general studies courses with a concentration of four to five courses in an area of special interest. The four optics, laser and fiber optics courses, along with laser safety, were offered as a package of electives to GET students. Graduates of this "GET/Photonics Option" have similar employment and transfer experiences as graduates of the original PET program. The photonics option adds to the number of students in the PET program courses at a time when class size is closely scrutinized. All photonics related lab courses are restricted to 12-14 students, however, because of room size and safety issues.

\subsection{Fiber optics certificate online}

A one-semester Certificate in Fiber Optics Technology was proposed shortly after the PET program was approved in 1997. The certificate was intended to allow students to quickly enter the workforce and it provides an entry point for students who wanted to matriculate in the PET program but do not have the prerequisite math courses. In addition to a laser safety course, the certificate consists of two laboratory based technology courses, optics and fiber optics, and a telecommunications overview course. An elective course in mathematics or computer science is chosen for applicability to employment or to prepare students to enter an associate degree program. Politics within the Community College system prevented the certificate from being approved until the fall of 2000 , at which point there was little demand for entry level fiber optics workers.

At the same time, the Connecticut Distance Learning Consortium was seeking certificate and degree programs to offer by distance learning via the Internet. Three Rivers received a $\$ 25,000$ grant to adapt the Fiber Optics Certificate to distance learning. Professor Randall Seebeck was hired to create the curriculum for the fiber optic and telecommunications courses suitable for web-based delivery. A "math for optics" course was also created to provide students with a math refresher on the topics that would appear in future certificate courses. Additional support for curriculum development was provided by the Connecticut College of Technology: Curriculum Reform Project, a NSF-ATE grant to the CT Community College system's College of Technology program. The online certificate curriculum was subsequently adopted as a photonics option to the College of Technology associate degree in Technology Studies, which is available at all twelve of Connecticut's community colleges.

The telecommunications industry downturn has resulted in few traditional students registering for the certificate program, however, it has been used to deliver incumbent worker training to employees of JDS Uniphase (where one course was delivered by distance learning) and 3M Optical Systems. The 3M program is funded by a grant from the U.S. Department of Labor to the Connecticut Business and Industry Association. The innovative delivery involves company mentors who are available to assist with technical questions and motivate students who fall behind. The optics course, Introduction to Photonics, uses printed text and web applets as well as "home lab experiments" based on the OSA (Optical Society of America) Optics Discovery Kit. Students work at home or on the job in small groups to perform experiments such as measuring the index of refraction of gelatin cubes, exploring image formation with lenses, and determining the diameter of a hair by diffraction. The fiber optics course includes on-site laboratory experiments created by the instructor with the assistance of $3 \mathrm{M}$. Traditional students are required to perform lab experiments at Three Rivers during a two day residency. Industry students have commented that although some of the labs are very similar to what they do on the job, the course has given them an understanding of what they do and why they do it. 


\subsection{Project PHOTON}

In 2000, the New England Board of Higher Education received funding for PHOTON, a professional development, curriculum enhancement and laboratory improvement project funded by the National Science Foundation Advanced Technology Education program. The authors of this paper are Principle Investigator (JD) and a participant (RS) in project PHOTON, which has allowed Three Rivers to tap into a New England-wide network of educators and industries. PHOTON has benefited the Three Rivers Photonics program in many ways.

- NEBHE marketing and dissemination efforts for PHOTON include the College and its participants, increasing the PET program visibility

- Curricula developed for PHOTON (text and laboratory experiment manual) are in use at the College.

- The College received a PHOTON lab kit (half the cost paid by the grant), which has been used both on campus and for various training programs off-campus.

- Members of the PHOTON Industry Advisory Committee have also assisted the college in obtaining donations, and providing technical support and assistance.

\section{Growing in decline: 2001-present}

\subsection{Curriculum changes adapt to changing conditions}

After a surge in enrollment in the first three years, the number of students in the Photonics Engineering Technology program began to drop; fewer than 10 new students enrolled in Fall 2002. Several factors have contributed to the loss of students, including news media proclamations that "fiber optics is dead" and the loss of the JDS Uniphasesponsored scholarship for photonics students. A more fundamental problem is that the word "photonics" is unknown to most high school students and their parents. If students have heard the term, they tend to associate it with optical fiber and telecommunications. An informal survey of 25 students attending the vocational-technical high school next door to the college revealed that not one student could define the term and most had never heard of it.

While the fiber optics industry awaits resurgence, Connecticut has seen growth in other areas of photonics. Companies producing industrial lasers and laser systems and precision optics as well as laser job shops have been seeking new employees in recent months. PET graduates have also found employment in the lighting industry. In response to changing employment opportunities and to give students a broader look at the industry, the PET curriculum underwent the third modification in its five year history in 2001-2002. A course in Laser Electronics was added, replacing the more generic Electronics II and allowing better integration of optics and electronics courses. Two required courses, Digital Electronics and Calculus II, were replaced by a technical elective and a math/science elective respectively. This affords students the opportunity to tailor the program to their own interests and to take courses such as CAD or manufacturing processes, and to study chemistry or statistics.

The final curriculum change, to be effective Fall, 2003, is the reorganization of the first two semester of optics, formerly Geometric Optics and Wave Optics. The new courses, Introduction to Optics and Applied Optics, cover the same material as the previous courses, but the first semester includes interference, diffraction, polarization and sources of light, providing a broader view of the subject. Removing more intensive topics such as matrices and aberrations to the second semester allows students to begin the program at a lower math level. The course will also be more appealing as a technical elective to students in other programs. The Photonics Engineering Technology curriculum is shown in Table 2. Developmental courses in Math and English are not indicated, but may be required after admissions placement testing.

In addition to changes to make the Photonics Engineering Technology degree more flexible and attractive to students, a Photonics/Electrical Engineering Technology double major was created allowing students in either program to receive both degrees taking only four additional courses. For students who earn Tech Prep college credits while in high school, both degrees may be earned in two years.

\subsection{Laboratory expansion}

Program graduates working in industry increasingly reported that they were expected to be knowledgeable about various instruments and procedures that had not been addressed in their laboratory courses. A new proposal to NSF was designed to address this situation. In January 2002, a $\$ 43,000$ grant was received from the Course, Curriculum and Laboratory Improvement program (NSF-CCLI) for the development of an advanced laboratory for lightwave communications. The CCLI grant builds on the earlier ILI grant that established the Lightwave Communications Laboratory. Instrumentation specified in the CCLI proposal includes an optical spectrum analyzer, single mode lasers, modulators and WDMs, and an EDFA experimentation kit. 
Table 2. Suggested plan of study for Photonics Engineering Technology students, Fall 2003

\begin{tabular}{|c|c|}
\hline Course number/name & Credits \\
\hline PHO $105 \quad$ Laser Safety & 0.5 \\
\hline PHY 140 Introduction to Optics/Lab & 4 \\
\hline EET 1100/1 Circuits I/Lab & 5 \\
\hline MATH 141 Precalculus & 4 \\
\hline ENG 111 College Composition & 3 \\
\hline Semester I total & 16.5 \\
\hline PHY 141 Applied Optics/Lab & 4 \\
\hline EET1110/1 Circuits II/Lab & 4 \\
\hline EET1120/1 Electronics I/Lab & 4 \\
\hline MATH 151 Calculus I & 4 \\
\hline Writing in the Workplace & 3 \\
\hline Semester II total & 19 \\
\hline PHO 230 Laser Electronics/Lab & 4 \\
\hline $\begin{array}{ll}\text { PHO } 240 & \text { Introduction to Lasers/Lab }\end{array}$ & 4 \\
\hline Math/Science Elective & 3 \\
\hline Humanities elective & 3 \\
\hline Technical Elective & $3-4$ \\
\hline SemesterIII total & $17-18$ \\
\hline PHO $250 \quad$ Fiber/Integrated Optics/Lab & 4 \\
\hline PHO 290 Advanced Laser Topics & 3 \\
\hline EET 2140/1 Telecomm. I/Lab & 4.5 \\
\hline Social Science elective & 3 \\
\hline Semester IV total & 14.5 \\
\hline
\end{tabular}

The telecommunications industry downturn has had an unexpected bright spot; laboratory equipment and instrumentation is inexpensive and companies find tax deductible donations to the College attractive. Due to a state budget crisis and severe cuts to the college budget, the college was unable to make a cash match to the equipment portion of the grant. However, the industry downturn resulted in large donations from downsizing companies, including two complete fiber optics workstations, two Newport fiber optics education kits, and two Newport optics education kits from JDS Uniphase. In addition, once prohibitively expensive components are available through Internet auction and surplus sites at pennies on the dollar. The combination of declining prices for instrumentation and donations from industry have allowed the project to complete purchase of all the requested equipment as well to purchase additional tools and inspection instruments to supplement the original lightwave lab.

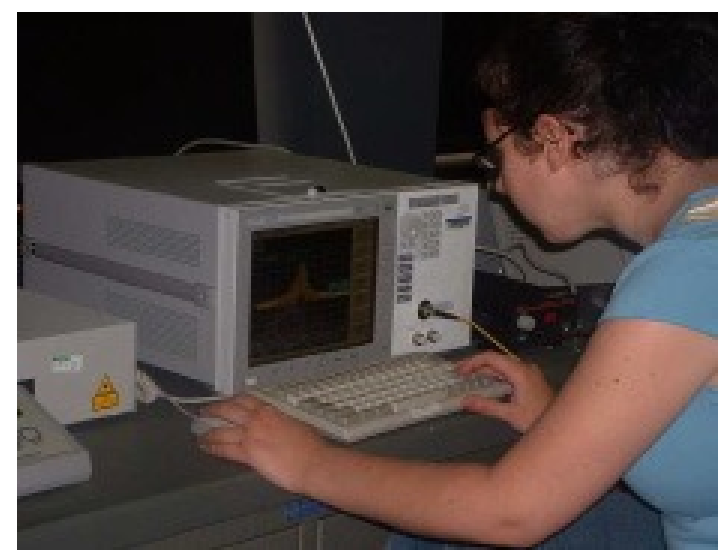

Fig. 2 Students use the optical spectrum analyzer to study laser modes in the Advanced Lightwave Communications Lab (2003) 
Table 3 lists the equipment purchased (or in some cases donated) for the advanced lightwave communications laboratory. Three stations are specified, and students rotate through the experiments. While the overall curriculum is still a work in progress, students in Advanced Laser Topics have worked with the optical spectrum analyzer to observe spectra of laser and LED sources; experiments with the EDFA kit and DWDM station are currently under development. When completed, lab experiments will be on the PET program web site, linked from the college web site (www.trcc.commnet.edu).

Table 3 Advanced laboratory for lightwave communications.

\begin{tabular}{|l|l|}
\hline \multicolumn{2}{|l|}{ Station $1 ;$ passive components } \\
\hline 1 & $\begin{array}{l}\text { Agilent Optical Spectrum Analyzer with white light source } \\
\text { and wavelength calibrator }\end{array}$ \\
\hline 1 & fiber coupler \\
\hline Station $2 ;$ active components \\
\hline 1 & Opto Sci EDFA laboratory kit \\
\hline Station $3 ;$ DWDM \\
\hline 1 each & JDSU DFB lasers $1338 \mathrm{~nm}$ and $1358 \mathrm{~nm}$ \\
\hline 2 & WDM coupler \\
\hline 2 & laser butterfly mount \\
\hline 2 & fiber coupled detector \\
\hline 2 & TE cooler \\
\hline 2 & LD driver w/cable \\
\hline 2 & Agilent Arbitrary Waveform Generator \\
\hline 2 & Agilent 100 MHz oscilloscope \\
\hline
\end{tabular}

The acquisition of additional workstations meant the PET program was again in need of additional laboratory space. A third laboratory was created to house the equipment for the advanced lightwave laboratory. The new Lightwave Communications Laboratory is next to the original photonics laboratory, now called the "Laser/Optics Lab". The two are connected by a stockroom, which houses electronic and fiber optics supplies. The new space is shared with the electrical engineering technology program, which uses it for a lab courses in telecommunications. Since the laboratory workstations are on wheels, instructors have flexibility in setting up the lab for each group of students.

\section{Marketing and recruitment}

By the time the third class of photonics technicians graduated in 2001, the first graduates were already being downsized from their telecommunications related jobs. The challenges to the program in the past two years have been to broaden the curriculum to include more laser physics and applications, increase the variety of hands-on laboratory experiences, and to attract increasingly skeptical students. The first two challenges have been well addressed, but the third remains elusive. "Evangelists for optics", the Photonics Engineering Technology faculty feels that once students have seen a little of the subject, they will want to know more. The time to introduce students is at the start of their high school career (or even earlier) so they can take appropriate math and science courses that will lead to college success. Initiatives to introduce high school students to optics include:

- Development of Tech Prep 2+2 agreements with area high schools. The first such program will begin with Plainfield (CT) High School, a PHOTON participating institution, in Fall 2003. Plainfield High School students will receive up to 14 college credits for completing a program that includes math through Algebra II, English communications, physics and Introduction to Optics.

- Creation of scholarships for photonics students. The College has received grants from SPIE for the past two summers, allowing high school students to explore photonics technology by taking Introduction to Photonics. Approximately $\$ 4300$ pays for tuition, fees, books and supplies for up to 10 students taking the four credit laboratory course. Three of the 10 students from the Summer 2002 scholarship group are now enrolled full time in the Photonics Engineering Technology program. Additional scholarship assistance is being sought from both 
funding agencies and industry. For Fall 2003, scholarships were made available to Three Rivers photonics students from the NSF Computers Science, Math, and Engineering Scholarships (NSF-CSEMS) grant awarded to the Community College system's College of Technology. Four new students will enroll in this program, which seeks to increase the number of science, math, engineering and technology students graduating from two and four year programs. Scholarships not only increase the number of students attending college, but also create marketing opportunities for the Photonics program.

- Aggressive recruitment of new students, aided by the college's SPIE student chapter's educational light show. A member of the faculty or a student volunteer attends each of the college's tech nights and college fairs, and high school teachers receive mailings throughout the year inviting them to bring student groups to visit the laboratories. Although it is a fairly simple matter to interest students in optics/photonics, convincing parents that the program will lead to a career is a more difficult challenge. New marketing materials being developed emphasize "pathways" available to our graduates, including transfer to four-year programs as well as immediate employment. Figure 3 shows the College's "rivers" logo incorporated into the pathways theme on a new program brochure. The new brochure also refers to Laser Optics Technologies, which include the degree programs in photonics and general engineering/photonics. The term "photonics" is introduced and defined inside the brochure.

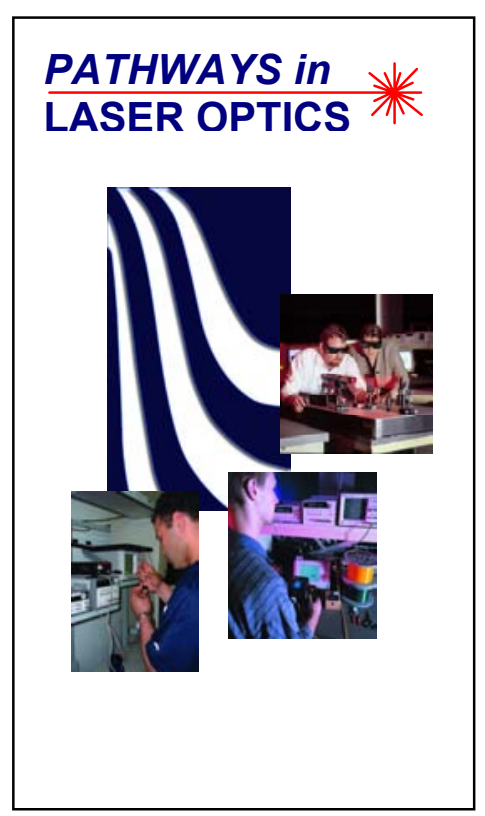

Fig. 3 New marketing brochure

The new strategies have resulted in increased enrollment of day students in 2003. The day program tends to attract younger students who are recent high school graduates. Typically these students are more interested in transfer to a four-year university and less reluctant to relocate for employment than older students, who most often are interested in finding local employment after graduation. A significant increase in the evening student population is not expected until the employment situation improves.

\section{Conclusion}

Three Rivers Community College has successfully implemented an associate in science degree program in Photonics Engineering Technology and a photonics option to an associate in applied science degree in General Engineering Technology. Long term success of the program depends on the ability to attract new students in sufficient numbers. Increasing curriculum flexibility and emphasizing transfer agreements with four-year colleges and universities are strategies designed to attract and retain students while the industry remains sluggish. It is hoped that when the industry recovers, the Photonics Engineering Technology program will be well situated to provide technicians to support the photonics companies of southern New England and beyond. 


\section{References}

1 National Photonics Skills Standard for Technicians, Center for Occupational Research and Development, CORD, Waco, TX, 1995.

\section{Acknowledgements}

\section{FOTEP}

Funded in-part by the Advanced Technological Education program of the National Science Foundation (\#ATE 9553762). Principal Investigator, Nicholas Massa, Springfield Technical Community College; Co-Principal Investigators Fenna Hanes (Project Manager), New England Board of Higher Education; James Masi, Western New England College; David Maack; Consultant Elias Awad, Wentworth Institute of Technology.

\section{NCTT}

Funded in-part by the Advanced Technological Education program of the National Science Foundation (\#ATE 9751990). Principal Investigator, Founding Principal Investigator, James Masi, (retired); Executive Director Gordon Snyder, Springfield Technical Community College; Co-Principal Investigators Nicholas Massa (returned to faculty assignments) Springfield Technical Community College; Fenna Hanes, New England Board of Higher Education; Gary Mullet, Springfield Technical Community College.

\section{PHOTON}

Funded in-part by the Advanced Technological Education program of the National Science Foundation.(ATE \#ATE 0053284) Principal Investigator, Judith Donnelly, Three Rivers Community College; Co-Principal Investigators Fenna Hanes (Project Manager), New England Board of Higher Education; John Swienton, Exfo USA, Inc.; Senior Personnel Nicholas Massa and Barbara Washburn, both Springfield Technical Community College.

Connecticut College of Technology: Curriculum Reform Project

Funded in part by the Advanced Technology Education program of the National Science Foundation (ATE\# ATE 0101654) Principal Investigator Karen Wosczyna-Birch, Tunxis Community College; Co-Principal Investigators Lennard Lema,; Scott Speaker, Tunxis Community College; Lauren W. Kaufman, Connecticut Business and Industry Association; Ronald S. Adrezin, University of Hartford.

\section{College of Technology Scholarship Grant}

Funded in part by the Computer Science, Engineering and Mathematics Scholarship program of the National Science Foundation (CSEMS \#0123007) Principal Investigator Karen Wosczyna-Birch, Tunxis Community College; Co-Principal Investigators John S. Pazdar, Lauren W. Kaufman, Connecticut Business and Industry Association; Robert Fortier, Manchester Community College; Robert Tremblay

\section{Development of a Laboratory for Lightwave Communications}

Funded in part by the Instrumentation and Laboratory Improvement program of the National Science Foundation (ILI \#9851432) Principal Investigator Judith Donnelly, Co Principle Investigator, Raymond Hasse, both of Three Rivers Community College.

\section{Development of an Advanced Laboratory for Lightwave Communications}

Funded in part by the Course, Curriculum, and Laboratory Improvement program of the National Science Foundation (CCLI \#0126665) Principal Investigator Judith Donnelly, Co Principle Investigators, Randall Seebeck and Brian Kennedy, all of Three Rivers Community College. 